\title{
Correction to: Low Life Course Socioeconomic Status (SES) Is Associated with Negative NEO PI-R Personality Patterns
}

\author{
Charles R. Jonassaint ${ }^{1} \cdot$ Ilene C. Siegler ${ }^{1,2} \cdot$ John C. Barefoot ${ }^{2} \cdot$ Christopher L. Edwards $^{2,3}$. \\ Edward C. Suarez ${ }^{2} \cdot$ Redford B. Williams $^{1,2,3,4}$
}

Published online: 31 July 2020

(C) International Society of Behavioral Medicine 2020

\section{Correction to: International Journal of Behavioral Medicine https://doi.org/10.1007/s12529-009-9069-x}

After the publication of original article, the Editor was notified by Duke University that they have determined the authorship to be incomplete. Consequently, Dr. Edward Suarez has been added as a co-author to this article to represent his contribution to the conception and design of the work and acquisition of the data.

Publisher's Note Springer Nature remains neutral with regard to jurisdictional claims in published maps and institutional affiliations.

The online version of the original article can be found at https://doi.org/ 10.1007/s12529-009-9069-x

Redford B. Williams redfordw@duke.edu

1 Department of Psychology and Neuroscience, Duke University, Durham, NC, USA

2 Department of Psychiatry and Behavioral Sciences, Duke University Medical Center, Durham, NC, USA

3 Department of Medicine, Duke University Medical Center, Durham, NC, USA

4 Department of Psychiatry, Behavioral Medicine Research Center, Duke University Medical Center, P.O. Box 2969, Durham, NC, USA 